\title{
A leitura hipertextual: da percepção visual às operações cognitivas
}

\author{
Fernanda Franco Tiraboschi* \\ Francisco José Quaresma de Figueiredo** \\ Resumo
}

Neste texto, de caráter teórico, temos como objetivo discutir os elementos articulados no processo de leitura tanto de texto impresso quanto hipertextual, no intuito de contribuir para as discussões envolvendo o hipertexto. Para tanto, nos apoiamos nas abordagens ascendente, descendente e sociointeracionistas de leitura (CARREL et al., 1995; DURAN, 2009; FAIRCLOUGH, 1989; GOODMAN, 1976; HUDSON, 2007; LEFFA, 1999), no intuito de discutir as mudanças relacionadas aos fenômenos envolvidos no processo de compreensão leitora. Discutiremos, também, as características do hipertexto, bem como sua leitura a partir da abordagem ecológica da cognição (LÉVY, 2004), confrontando, também, as visões de autores como Snyder (1998) e Xavier (2002). Desse modo, procuramos abordar aspectos relacionados ao processo de leitura, em especial o de hipertextos, considerando os fatores incidentes tanto no sistema de percepção visual quanto no processamento cognitivo de informações relacionadas à linguagem verbal escrita. Por fim, consideramos que nenhuma leitura é linear, uma vez que a cognição humana funciona por meio de associações. Portanto, a leitura tanto de textos impressos quanto de textos virtuais pode ser considerada hipertextual.

Palavras-chave: Leitura. Hipertexto. Percepção visual. Cognição. Compreensão hiperleitora.

Recebido em: 30/01/2017

Aceito em: 25/06/2017

* Universidade Federal de Goiás - (UFG). Mestra em Letras e Linguística pela Universidade Federal de Goiás.

** Universidade Federal de Goiás - (UFG). Mestre em Linguística pela Universidade Federal de Goiás, Doutor e Pós-Doutor em Linguística Aplicada pela Universidade Federal de Minas Gerais. É Professor Titular de Língua Inglesa da Universidade Federal de Goiás. 


\section{Introdução}

Ao longo da história, mudanças significativas nos modos de ler ocorreram à medida que os textos foram se enquadrando em novos espaços de veiculação. $\mathrm{Na}$ fixação da linguagem articulada, a humanidade recorreu a diversos objetos simbólicos, instrumentos e suportes. Atualmente, lidamos com textos manuscritos, impressos e virtuais nos diversos âmbitos de nossas práticas discursivas. Tal fato tem instigado pesquisadores interessados nos avanços tecnológicos da escrita e da leitura a estudar e refletir, com maior empenho, as características desse novo suporte virtual e suas implicações para o processo de leitura e, por conseguinte, para a forma de conhecer do homem inserido no mundo contemporâneo.

No que se refere aos textos no formato digital, o hipertexto vem sendo o foco de discussões de diversos autores interessados em investigar as reais diferenças e semelhanças entre o texto impresso (definido por alguns autores como linear) e o hipertexto (definido como não linear). A questão central gira em torno da influência que a apresentação textual teria sobre as operações cognitivas articuladas durante o processamento de informação na compreensão leitora. Por um lado, autores como Snyder (1998) e Xavier (2002), entre outros, defendem a visão de um hipertexto estritamente ligado à informática e diferente do texto impresso no que se refere ao processamento da leitura. Por outro lado, autores como Coscarelli (2012), Lévy (2004), Marcuschi (2005), entre outros, defendem uma visão de hipertexto ligado a uma condição cognitiva que serve de metáfora para a leitura, e não como um mero produto textual que mobiliza operações cognitivas totalmente divergentes daquelas articuladas na leitura de um texto impresso. Diante dessas considerações, propomos, neste texto, discutir os elementos articulados no processo de leitura tanto de texto impresso quanto hipertextual no intuito de contribuir para as discussões envolvendo este último.

Cumpre lembrar que a "leitura" de que trata este texto é a leitura da linguagem verbal escrita, pois também é possível falar em leitura de imagens, de gestos, de expressões faciais e de mundo.

Enfocaremos, nessa empreitada, um determinado ponto de vista, a saber, ao discutir os modos e processamento da leitura tanto de textos impressos quanto de hipertextos, podemos observar que nem a leitura de hipertextos nem a leitura de impressos são lineares, e a hipertextualidade, é, na verdade, uma metáfora para a cognição humana. Nesse sentido, toda leitura possui uma característica hipertextual no que se refere ao seu modo de perceber, captar e processar informações. 
Devido à natureza complexa do processo de leitura, pesquisadores interessados em compreender os fenômenos envolvidos no ato de leitura têm constantemente reformulado a concepção de leitura e dos participantes desse processo, ora privilegiando o texto e seus aspectos internos, ora privilegiando o leitor e os fatores cognitivos na leitura, ora ainda considerando o contexto social em que o autor, o texto e o leitor estão inseridos. Desse modo, em um primeiro momento, será feita uma breve retrospectiva teórica concernente às abordagens de leitura, com vistas à discussão das mudanças no foco do objeto de análise e, por conseguinte, nas concepções de texto, leitura e leitor. Posteriormente, será feita uma discussão sobre as características do hipertexto, bem como sobre aspectos concernentes à leitura desse formato textual. Começamos, então, pela discussão dos elementos privilegiados na abordagem de leitura, conhecida como ascendente.

\section{Abordagem ascendente}

Neste prisma, pode-se observar uma visão de leitura fundamentada na decodificação de elementos linguísticos, tomando o texto como uma unidade de análise suficiente para a compreensão da leitura. Nesse sentido, para que o leitor ative a compreensão, é necessário que ele possua a competência linguística na língua em que o texto foi escrito. Em outros termos, a habilidade de reconhecer e extrair significados das palavras torna-se fundamental nesse modelo de leitura, uma vez que o texto é visto como uma fonte plena e única de sentido fluindo em direção ao leitor, por isso a utilização do termo ascendente (bottom-up em inglês). Conforme afirma Leffa (1999),

[o] aspecto mais importante da leitura, nesta perspectiva textual, é a obtenção do conteúdo que subjaz ao texto. O conteúdo não está no leitor, nem na comunidade, mas no próprio texto. Daí que a construção do significado não envolve negociação entre o leitor e o texto e muito menos atribuição de significado por parte do leitor; o significado é simplesmente construído através de um processo de extração. Tudo está no texto, mas separado em duas camadas: uma camada profunda, que é o conteúdo a ser acessado pelo leitor, e uma camada superficial, que recobre o conteúdo, mostrando-o com maior ou menor clareza, dependendo justamente de sua transparência. (LEFFA, 1999, p.6).

Segundo Gough (1972, citado por HUDSON, 2007), no ato de leitura, o movimento articulado pelos olhos é linear (pelo menos nos textos em português, 
inglês, etc.), isto é, o sistema de percepção visual capta palavra por palavra, letra por letra, partindo sempre da esquerda para a direita, de cima para baixo. Adicionalmente, o referido autor enfatiza a correspondência grafema-fonema, bem como o processamento de informações já existentes no texto como aspectos cruciais na compreensão.

É importante observar que a percepção visual de qualquer signo passa por um estágio que compreende a captação e o processamento mental da informação visual. Dessa forma, a luz incide sobre a superfície onde um determinado signo se encontra, é refletida e, então, captada por um sensor, o olho, que utiliza a córnea, a pupila, o cristalino e a retina para a recepção dos fenômenos luminosos. Seguidamente, o nervo ótico transporta as informações para o córtex cerebral, o que possibilita as sinapses da percepção (ROBERT, 2000).

De acordo com Santos e Simas (2001), considerar a percepção visual como um fenômeno linear pode ser inapropriado, uma vez que, na prática, o processo é bem mais complexo. Ademais, "a percepção e processamento visual da forma são processos dinâmicos e contínuos e podem envolver tanto um processamento de baixo para cima ou bottom-up como um processamento de cima para baixo ou top-down" (SANTOS; SIMAS, 2001, p. 163). ${ }^{1}$

De acordo com Foucambert (1994, p. 6), "ler é explorar a escrita de uma maneira não-linear [...]. [J]amais se chega ao significado de um texto pela soma do sentido das sucessivas palavras que o compõem". Vemos, portanto, que a compreensão do processo de leitura não pode ser reduzida a simples decodificação de elementos linguísticos de forma linear, é preciso considerar não só a dimensão físico-fisiológica, mas também as dimensões cognitiva e social. Coscarelli (1999) traz uma definição de leitura que vai nessa mesma direção. Segundo a autora, a leitura é

um processo complexo que envolve desde a percepção dos sinais gráficos e sua tradução em som ou imagem mental até a transformação dessa percepção em ideias, provocando a geração de inferências, de reflexões, de analogias, de questionamentos, de generalizações, etc. (COSCARELLI,1999, p.33).

$1 \mathrm{Na}$ abordagem psicológica da percepção visual, top-down refere-se ao processamento não linear que, por sua vez, é uma denominação utilizada pelos modelos cognitivos de percepção visual. Por outro lado, o termo bottom-up é utilizado para fazer referência ao processamento visual de formas, sintetizadas no córtex visual, a partir das informações que chegam e são analisadas na retina (SANTOS; SIMAS, 2001). 
A partir do exposto, é possível constatar uma grande variedade de aspectos pertinentes ao ato de ler, os quais não são considerados pela abordagem ascendente na compreensão do processo de leitura. Alguns dos aspectos mencionados acima, como a postura ativa do leitor frente ao texto, foram percebidos e incorporados no estudo do ato de leitura pela abordagem descendente ou top-down, como vemos na seção seguinte.

\section{Abordagem descendente}

A partir de algumas críticas em relação às inconsistências teóricas e práticas da perspectiva estruturalista, surgem as propostas das abordagens cognitivistas que, por sua vez, direcionam o foco de análise aos processos mentais articulados pelo leitor na prática de leitura. Nessa linha, o texto já não é mais pleno de sentido, isto é, a tarefa da construção de sentido é atribuída ao leitor, que mobiliza seu conhecimento linguístico, textual, enciclopédico e de mundo para desempenhá-la.

O processamento da leitura, nessa perspectiva, se dá através de uma série de operações articuladas pelo leitor, tais como a predição, estabelecimento de hipóteses sobre o que o texto aborda a partir da ativação de seu conhecimento prévio e a busca da confirmação através das pistas deixadas pelo leitor. Goodman (1976), um dos precursores desse modelo, concebe a leitura como

um processo seletivo. Envolve o uso parcial de pistas linguísticas mínimas disponíveis selecionadas a partir do insumo perceptual baseadas na expectativa do leitor. Como essa informação parcial é processada, tentativas de decisões são feitas para ser confirmadas, rejeitadas, ou refinadas com o progresso da leitura. (GOODMAN 1976, p. 498. Tradução nossa. ${ }^{2}$ ).

Nesse sentido, o texto não mais apresenta um sentido ao leitor, mas estimula a busca do sentido já construído, de alguma forma, na mente do leitor. A esse respeito, Leffa (1996, p. 14-15) argumenta que "a compreensão não começa pelo que está na frente dos olhos, mas pelo que está atrás deles".

Leffa (1999) ainda salienta que as informações armazenadas na memória do leitor desempenham um papel extremamente importante na leitura, uma vez que ele pode omitir, trocar e acrescentar palavras que não constam no texto sem

2 No original: "a selective process. It involves partial use of available minimal language cues selected form perceptual input on the basis of the reader's expectation. As this partial information is processed, tentative decisions are made to be confirmed, rejected, or refined as reading progresses." 
perceber. Nessa direção, o autor explica tal fato argumentando que o leitor não lê necessariamente o que está impresso no texto, mas "o que sua mente mandou seus olhos procurar" (LEFFA, 1999, p. 13). Para Smith (1999), a partir da utilização da predição e do contexto, o leitor pode ativar os esquemas ${ }^{3}$ na memória para construir significados durante o processo de leitura.

Devido ao seu caráter mentalista, essa vertente foi, também, superada pelas abordagens discursivas que, a partir das perspectivas interacionistas, ampliam o escopo da atividade de leitura, levando-se em conta o texto, sujeito-leitor (visto como participante ativo) e as condições de produção do discurso na construção de sentido de um determinado texto.

\section{Abordagens interacionistas}

É possível observar, na literatura sobre leitura, uma vasta gama de modelos interacionistas evidenciando vieses ora de cognitivismo ora de sociointeracionismo. Em outras palavras, alguns modelos tendem a enfatizar a interação entre os componentes dos processos cognitivos na leitura, ao passo que outros modelos enfatizam não só a interação entre autor-texto-leitor, mas também a interinfluência do contexto sociocultural em que estes estão inseridos (CARREL et al., 1995; DURAN, 2009; HUDSON, 2007; LEFFA, 1999). Assim, serão discutidos alguns pontos pertinentes aos principais modelos provenientes das abordagens interacionistas.

Hudson (2007) lista três vertentes que orientam o estudo do processo de leitura sob o paradigma interacionista. A primeira enfatiza o papel das habilidades cognitivas de forma independente da compreensão geral. A segunda enfoca a interação entre o conhecimento prévio e o texto. E, por fim, a terceira focaliza os aspectos sociais, contextuais e as relações de poder incidentes na construção de sentido.

O primeiro, considerado como visão autônoma de leitura (STREET, 1993), possibilita a investigação do processo de leitura fora de um contexto por meio de trechos ou fragmentos isolados, tecnologias que captam o movimento dos olhos, velocidade do protocolo de respostas etc. Nesse viés, a leitura consiste em um processo independente de aspectos contextuais, isto é, o contexto pode auxiliar, mas não tem uma influência tão direta quanto o processo cognitivo. É possível

3 Os esquemas podem ser entendidos como blocos de conhecimentos pré-existentes, armazenados na memória e que representam situações vivenciadas ou familiares. (ANDERSON; PEARSON, 1984). 
observar que esse modelo se ocupa em observar a interação dos elementos cognitivos no processamento de informações textuais.

A segunda orientação destaca a interação entre o conhecimento de mundo e experiências do leitor e o texto; em outros termos, o foco é colocado na predição do sentido intencionado pelo autor a partir da ativação do conhecimento prévio e confirmação através da leitura. Para Hudson (2007), tal visão está vinculada à discussão de Smith (1994) de que as línguas possuem uma superfície estrutural na qual se evidenciam as características linguísticas e uma superfície mais profunda de onde se obtém o sentido de uma determinada mensagem. Vê-se que, em tal orientação, o hibridismo das abordagens ascendente e descendente se revela, uma vez que a leitura é vista como um processo que

não apenas enfatize o papel do leitor ou do texto, mas que aceite que o produto da relação entre leitor e texto é o sentido da leitura. Isso quer dizer que a interação entre texto e leitor ocorre de maneira a se retomarem ora a perspectiva do leitor, ora a do texto, conforme a necessidade para cada situação de leitura. (DURAN, 2009, p. 4).

$\mathrm{Na}$ terceira orientação, o contexto social é visto como um aspecto imprescindível ao entendimento do processo de leitura e busca subsídios teóricos nos Estudos de Novos Letramentos. Assim, para examinar como ocorre o processo de leitura, é importante levar em conta as práticas de letramento que, por sua vez, englobam questões pertinentes às convenções relativas ao papel da leitura e escrita em um determinado contexto social, assim como as expectativas dos leitores e a seleção dos tópicos e gêneros apropriados a cada situação. Nesse viés, o processo de leitura é interativo, na medida em que envolve não só o processamento dos elementos internos do texto e o conhecimento de mundo do leitor, mas também por admitir que as práticas de letramento, tanto leitura quanto escrita, não são neutras, isto é, estão sempre inseridas em contextos ideológicos envolvendo relações sociais de poder e de controle (FAIRCLOUGH, 1989; HUDSON, 2007).

É importante salientar que leitores e escritores, ao agirem através da linguagem para a construção de significados, se posicionam social, política, cultural e historicamente. Desse modo, entendemos que a língua não se refere a um sistema rígido, neutro e fechado em si mesmo, mas se trata de um fenômeno complexo, dinâmico, simbólico, mutável, fluido, híbrido, heterogêneo e adaptativo, uma vez que a língua se adapta aos usuários e estes a utilizam para se adaptarem ao contexto em que estão inseridos (BAKER, 2009; BLOMMAERT, 2012; KNOBLAUCH, 
2001; MAKONI; PENNYCOOK, 2007; RISAGER, 2006; entre outros). Podese dizer, ainda, que a língua é construída social e politicamente; portanto, é atravessada por relações de poder, tensões e conflitos ideológicos e afetivos.

A concepção de leitura, adotada neste texto, subjaz a esse conceito de língua discutido anteriormente e entende que, no processo de leitura, as construções de sentido são determinadas por fatores sócio-histórico-ideológicos e culturais. Dessa forma, o sentido só pode ser estabelecido a partir da interação do sujeitoleitor e os discursos veiculados em um dado texto. Moita Lopes (1996) corrobora essa concepção ao afirmar que ler é "saber-se envolvido em uma interação com alguém em um momento sócio-histórico específico e que o escritor, como qualquer interlocutor, usa a linguagem a partir de um lugar social marcado". Desse modo, “[1]er é se envolver em uma prática social” (MOITA LOPES, 1996, p. 142).

Nesta subseção, discutimos aspectos da leitura defendidos pelos modelos subjacentes à abordagem interativa, bem como explicitamos nossa concepção de leitura. Na seção seguinte, traçamos algumas considerações sobre os elementos e as características do hipertexto e de sua leitura.

\section{A noção do hipertexto}

A ideia precursora do conceito de hipertexto nos remonta à máquina imaginária de Vannevar Bush. Em seu artigo “As we may think”, publicado em 1945, o referido autor descreve um dispositivo denominado Memex (memory + index), no qual seria possível o armazenamento de uma grande quantidade de informações organizadas e disponibilizadas para fácil e rápido acesso (MOWERY; ROSENBERG, 2005). Para o autor,

[a] mente humana [...] opera por associações. Com um item em mãos, ela pula instantaneamente para o próximo que é sugerido pela associação de pensamentos, de acordo com uma intricada rede de possibilidades oferecida pelas células do cérebro. Ela tem outras características, é claro; as trilhas que não são frequentemente seguidas estão fadadas a desaparecer, os itens não são completamente permanentes, a memória é transitória. Além disso, a velocidade da ação, a complexidade das trilhas, os detalhes das imagens mentais, são mais inspiradores que tudo mais na natureza. (BUSH, 1945, citado por COSCARELLI, 2010, p. 124). 
Assim, percebemos que o desejo de Bush era o de criar um dispositivo que operasse da mesma forma ou de uma forma mais eficiente que a mente.

Posteriormente, o pioneiro da tecnologia de informação, Theodore Nelson, cunhou os termos hipertexto e hipermídia em seu projeto intitulado Xanadu, desenvolvido em 1965. A ideia do autor consistia na criação de um sistema que permitiria a escrita e a leitura de forma não sequencial. Nelson também partilhava do mesmo anseio de Bush, a saber, criar uma máquina capaz de compilar diversos blocos de textos, a qual possibilitaria a articulação, edição e leitura de documentos de forma semelhante ao funcionamento da mente no que se refere à produção de textos (LÉVY, 2004).

Embora a ideia de hipertexto tenha surgido com os norte-americanos Vannevar Bush e Theodore Nelson, os estudos que mais oferecem contribuições para o entendimento do hipertexto pertencem ao filósofo francês Lévy (1996, 2004). O autor desenvolve uma teoria sobre hipertexto, a qual atribui o nome de ecologia cognitiva. Para o autor, tal abordagem revela-se eficaz para essa empreitada, uma vez que ecologia implica a existência de relações e interações entre organismos vivos ou não, ao passo que a palavra cognitiva refere-se a uma forma de conhecer. Em outros termos, "a ecologia cognitiva constitui um espaço de agenciamentos, de pautas interativas, de relações constitutivas, no qual se definem e redefinem as possibilidades cognitivas individuais, institucionais e técnicas" (MARASCHIN; AXT, 2000, p. 91). Dessa maneira, Lévy (2004) concebe a ecologia cognitiva como uma disciplina que se ocupa em estudar sistematicamente a tecnologia informática na organização institucional das sociedades humanas.

Nessa abordagem ecológica da cognição, Lévy (2004) vê o hipertexto como um modelo de funcionamento da mente, isto é, a cognição é entendida como o efeito de redes complexas da mesma forma que o hipertexto é resultado de redes complexas interligadas entre si. A figura seguinte ilustra a noção de hipertexto do referido autor. 


\section{Figura 1: Modelo de hipertexto}

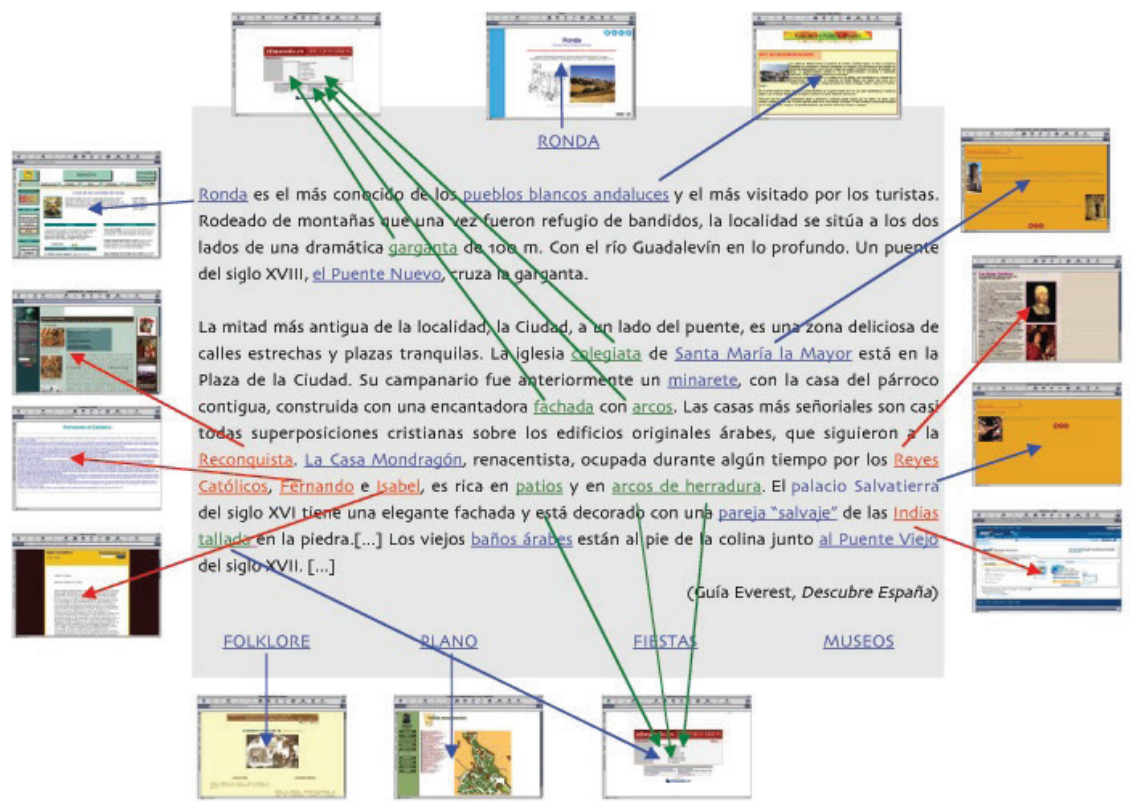

Fonte: $<$ https://cw121a5.wordpress.com/tag/hipertexto/>

Lévy (2004) propõe conceitos de hipertexto considerando suas dimensões técnica e funcional. Assim, para o autor,

tecnicamente, um hipertexto é um conjunto de nós ligados por conexões. Os nós podem ser palavras, páginas, imagens, gráficos ou partes de gráficos, sequências sonoras, documentos complexos que podem eles mesmos ser hipertextos. Os itens de informação não são ligados linearmente, como em uma corda com nós, mas cada um deles, ou a maioria, estende suas conexões em estrela, de modo reticular. Navegar em um hipertexto significa, portanto, desenhar um percurso em uma rede que pode ser tão complicada quanto possível. Porque cada nó pode, por sua vez, conter uma rede inteira. [...] Funcionalmente, um hipertexto é um tipo de programa para a organização de conhecimentos ou dados, a aquisição de informações e a comunicação. (LÉVY, 2004, p. 20).

Ao tratar do conceito de tecnologia da inteligência, ${ }^{4}$ Lévy (1996) lança mão das características do modelo de organização reticular da mente para descrever o

4 Inteligência é considerada por Lévy (2004) como um sinônimo de cognição. 
papel desempenhado por tal tecnologia. Nessa linha, para o autor "uma tecnologia intelectual, quase sempre, exterioriza, objetiviza, virtualiza uma função cognitiva, uma atividade mental" (LÉVY, 1996, p. 38). Vemos que, na visão do autor, a hipertextualização nada mais é do que a atualização dos processos articulados em rede na mente do autor e do leitor. A condicional seguinte encerra tal ideia:

se ler consiste em hierarquizar, selecionar, esquematizar, construir uma rede semântica e integrar ideias adquiridas a uma memória, então as técnicas digitais de hipertextualização e de navegação constituem de fato uma espécie de virtualização técnica ou de exteriorização dos processos e leitura. (LÉVY, 1996, p. 49-50).

Vale ressaltar que, embora Lévy $(1996,1999)$ utilize o termo "hipertexto informático", em vários momentos ao longo de suas obras, ele não considera o espaço virtual como uma condição sine qua non para a existência desse formato textual, já que para ele, "o hipertexto é talvez uma metáfora válida para todas as esferas da realidade em que significações estejam em jogo" (LÉVY, 2004, p. 15, grifo do autor).

Diferentemente, alguns autores relacionam o hipertexto ao contexto da informática. Snyder (1998) e Xavier (2002), por exemplo, atribuem ao hipertexto um caráter estritamente digital. De acordo com Snyder (1998, p. 126),

o hipertexto é um meio de informação que existe apenas on-line num computador. É uma estrutura composta de blocos de texto conectados por nexos (links) eletrônicos que oferecem diferentes caminhos para os usuários. O hipertexto proporciona um meio de organizar a informação de maneira não linear, tendo o computador como automatizador das ligações de uma peça de informação com outra. (SNYDER, 1998, p.126. Tradução nossa).

Conforme advoga Xavier (2002), o conceito de hipertexto aborda somente os formatos textuais que estejam no ambiente on-line interligados entre si de modo a formar uma rede. Adicionalmente, o referido autor enfatiza que tais hipertextos devem ser acessados por meio de um endereço eletrônico na World Wide Web.

Snyder (1998) indica, ainda, que há diferentes tipos de hipertextos e cada um apresenta suas particularidades. Desse modo, há aqueles que se assemelham aos textos impressos e aqueles que englobam diversos recursos hipermidiáticos. ${ }^{5}$ pode englobar não só textos, mas também sons, animações e vídeos (BUGAY; ULBRICHT, 2000). 
$\mathrm{O}$ autor ainda apresenta quatro categorias de hipertextos: os fechados, como hipercards, ${ }^{6}$ os que são sistemas de distribuição de hipertextos, como o sistema www; os que só permitem a leitura; e os que permitem ao usuário acrescentar textos, links, ou ambos.

Uma questão que preocupa os pesquisadores que estudam os gêneros emergentes no meio virtual é a consideração ou não do hipertexto com um gênero digital. Para Paiva (2004, p. 76), "gêneros textuais são como sistemas discursivos complexos, socialmente construídos pela linguagem, com padrões de organização facilmente identificáveis, dentro de um continuum de oralidade e escrita, e configurados pelo contexto sócio-histórico que engendra as atividades comunicativas". Nesse sentido, Marcuschi (2005, p. 25) argumenta que o hipertexto não pode ser considerado um gênero textual específico, mas consiste em "um modo de produção textual que pode estender-se a todos os gêneros dando-lhes neste caso algumas propriedades específicas".

A posição defendida neste artigo não restringe o hipertexto ao suporte digital, mas considera toda construção de sentido como uma rede hipertextual, isto é, o processamento mental da leitura, quer seja de textos impressos ou eletrônicos, não se dá de forma linear, mas mobiliza operações de modo reticular que apontam para diversas direções. Adicionalmente, a organização hipertextual é uma característica da natureza humana em diversos aspectos. Nesse sentido, Marcuschi (2005, s.n.) salienta que "o hipertexto seria, sobretudo, uma forma de se entender os modos de tessitura de sentidos e organização de nosso dizer. Não somos lineares por natureza, não somos uma sequência de racionalidade nem somos explicitude".

Além disso, a Linguística Textual e a Psicologia Cognitiva têm nos mostrado que o processamento de informações na leitura também funciona por meio de associações. Em outras palavras, ativamos modelos de situação, estados de coisas e experiências que nos ajudam em nossa compreensão leitora. Tais modelos, que são considerados estruturas complexas organizadoras de conhecimento, receberam diversos nomes, tais como esquemas (BARTLETT, 1933; FAUCONNIER, 1994; SMITH, 1999), frames (MINSKY, 1975), modelos mentais (JONHSON-LAIRD, 1983) para citar alguns exemplos. É possível observar, então, que há um consenso entre esses autores quanto ao fato de que nosso cérebro organiza o conhecimento em estruturas, as quais são mobilizadas através da ativação de um elemento que

6 Hipercard se refere a um programa utilizado antes do sistema WWW (world wide web) que proporcionava uma associação de bancos de dados a uma interface gráfica flexível e modificável pelo usuário (LASAR, 2012). 
liga a nova informação a uma informação já armazenada, construindo, assim, um novo conhecimento. Tal fato nos remete ao formato hipertextual, uma vez que se trata de um texto que fornece ligações para outros textos.

Buscou-se, nesta seção, apresentar elementos pertinentes à noção de hipertexto em termos de técnica e estrutura. Na seção seguinte, discutimos aspectos relativos aos modos e ao processamento da leitura hipertextual.

\section{Características relativas ao processo de leitura hipertextual}

Com o advento de novos suportes de veiculação textual, como, por exemplo, as telas dos computadores, um grande número de pesquisadores tem se debruçado na compreensão de como ocorre o processo de leitura de hipertextos, no intuito de observar a influência do suporte eletrônico nos modos de ler (CHARTIER, 2002; COSCARELLI, 2012; LÉVY, 2004; MARCUSCHI, 2005; PINHO, 2000; entre outros). Desse modo, buscamos articular pontos de vista divergentes, convergentes e complementares, no intuito de obter uma visão ampla e dinâmica do fenômeno em questão.

Chartier (2002) sinaliza uma preocupação em relação à habilidade de selecionar e distinguir os discursos e fontes de informação disponíveis no suporte eletrônico, visto que o hipertexto é capaz de integrar e distribuir textos e discursos diversos. Para o autor, os textos impressos garantiam uma maior credibilidade em termos de autoria e de qualidade nas informações comunicadas, diferentemente do hipertexto que possibilita uma maior abertura em relação à intervenção do leitor, considerado como um coautor. Entretanto, não se pode dizer que tal intervenção é uma característica apenas do hipertexto, visto que o leitor de impressos também pode fazer anotações ou acrescentar comentários no texto, assim como o leitor de hipertexto. Adicionalmente, como argumenta Coscarelli (2010, p. 157), “existem lugares apropriados para que o leitor se manifeste e faça suas intervenções e ele não pode modificar tudo o que quiser como um verdadeiro coautor".

No que se refere aos modos de leitura, Pinho (2000) discute algumas diferenças em relação à leitura de textos impressos e a leitura na tela de um computador. Assim, ele argumenta que

[u]m leitor ocidental lê textos impressos seguindo um caminho de leitura, formado por quatro pontos. A região de partida se dá primeiramente da esquerda para a direita da página, segue em diagonal de cima para baixo, ocorrendo novamente na linha 
seguinte, também da esquerda para a direita. $\mathrm{O}$ movimento forma um caminho que se repete linha após linha de maneira consecutiva, compondo um formato imaginário similar a consoante "Z". A partir disso, os conteúdos textuais são dispostos e lidos dentro de uma seqüência. (PINHO 2000, p. 171).

Como se pode observar, Pinho (2000) defende uma forma de leitura de impressos predominantemente linear, como se todo leitor seguisse sempre a mesma rota, sem interrupções para a leitura de referências ou notas de rodapé, sem recuar para reler uma passagem que não ficou clara ou avançar para outra parte que considera mais interessante.

Para Burgos (2006), a leitura de textos no suporte virtual toma uma rota distinta daquela descrita por Pinho (2000). Desse modo, a autora afirma que

[n]os sítios virtuais a leitura é iniciada a partir do centro do sítio virtual (ponto 1), em seguida o foco visual é dirigido para o lado superior esquerdo (ponto 2), para posteriormente chegar, em linha reta, até o lado superior direito (ponto 3). O caminho continua com uma descida em diagonal até o canto inferior esquerdo (ponto 4), continuando, em linha reta, até a extremidade inferior direita (ponto 5). (BURGOS, 2006, p. 4).

Cabe salientar que o ato de ler textos na tela é chamado, por alguns autores, de navegar. Pinho (2000, p. 335) diferencia o uso de alguns termos, utilizados no contexto informacional, que pertencem ao mesmo campo lexical do verbo navegar. Dessa forma, para ele, navegação refere-se à interconexão através de diversos computadores da rede localizados em diferentes servidores ou a ação de localizar outros sítios virtuais e suas interconexões, a partir da utilização dos browsers, que, por sua vez, são chamados de navegadores e podem ser considerados como um software utilizado para pesquisa em redes direcionado à recuperação e à exibição de cópias de arquivos.

Não se pode ignorar o fato de que o suporte que porta ou fixa um texto influencia na maneira de manuseá-lo. A evolução de suportes textuais permite não só gestos e modos de leitura distintos, mas busca fornecer vantagens sobre os suportes antecedentes. Ao discutir as mudanças nas formas de leitura decorrentes do advento gradativo de novos suportes, Chartier (2002) estabelece um paralelo entre os aspectos da leitura por meio do rolo de pergaminho (volumen) e do livro manuscrito ou impresso (códice). Assim, para o autor, a leitura do rolo 
era uma leitura contínua, que mobilizava o corpo inteiro, que não permitia ao leitor escrever enquanto lia, ao passo que o códice, manuscrito ou impresso, permitiu gestos inéditos (folhear o livro, citar trechos com precisão, estabelecer índices) e favoreceu uma leitura fragmentada, mas que sempre percebia a totalidade da obra, identificada por sua materialidade. (CHARTIER, 2002, p. 30).

Embora sejam perceptíveis as diferenças nos modos de manipular os suportes, é preciso ainda verificar, nas pesquisas, fatores que possam comprovar diferenças reais nas operações cognitivas envolvidas na compreensão de textos impressos e eletrônicos. Coscarelli (2006, p. 4) advoga que "toda leitura envolve colocar em prática diversas habilidades cognitivas que refletem o funcionamento de vários domínios de processamento. Ler não é realizar uma ou outra habilidade, mas um conjunto delas, que juntas resultam na construção de sentido(s)."

Ademais, a compreensão de textos, tanto impressos quanto hipertextos, depende de uma grande quantidade de conhecimentos compartilhados. Ativamos uma série de estratégias, tais como predição, levantamento de hipóteses, verificação de hipóteses, inferência contextual para a compreensão leitora. Embora, o formato hipertextual nos possibilite novas estratégias, como as de navegação (checar a veracidade de uma ou mais fonte; realizar leituras de busca de informações entre múltiplas páginas etc.), o leitor ainda articula as estratégias do formato impresso para sua compreensão de um hipertexto (KONISHI, 2003; TIRABOSCHI, 2015).

\section{Considerações finais}

A partir do que foi discutido, é possível ver que nenhuma leitura é linear, uma vez que a cognição humana funciona por meio de associações. Portanto, a leitura tanto de textos impressos quanto de textos virtuais pode ser considerada hipertextual. O hipertexto, na verdade, "potencializa uma característica que já era própria de todo o discurso" (RAMAL, 2002, p. 175). No que se refere à noção de leitura de hipertexto, a seguinte citação de Coscarelli (2006) resume, de uma forma sucinta e consistente, a posição tomada neste texto. Para a autora, "o que temos hoje com a informática é uma forma de ler e produzir textos mais próximos daquela que usamos mentalmente para processar as informações, ou seja, para pensar" (COSCARELLI, 2006, p. 7).

Neste artigo, procuramos abordar os aspectos relacionados ao processo de 
leitura, em especial o de hipertextos, considerando os fatores incidentes tanto no sistema de percepção visual quanto no processamento cognitivo de informações relacionadas à linguagem verbal escrita. Observamos que uma grande quantidade de informações é atualizada nos formatos impressos, manuscritos e digitais, constituindo, assim, as práticas de leitura na contemporaneidade. Observamos ainda que, embora a compreensão hipertextual mobilize novas estratégias cognitivas e metacognitivas, ela ainda necessita das estratégias já utilizadas na compreensão de textos impressos.

\title{
Hypertext Reading: from Visual Perception to Cognitive Operations
}

\begin{abstract}
This theoretical text discusses the elements articulated in the reading process of both printed text and hypertext, in order to contribute to the discussions involving hypertexts. To do so, we will rely on the bottomup, top-down, and socio-interactionist reading approaches (CARREL et al., 1995; DURAN, 2009; FAIRCLOUGH, 1989; GOODMAN, 1976; HUDSON, 2007; LEFFA, 1999) so as to discuss the changes related to the phenomena involved in the reading comprehension process. We will also discuss the main features of hypertexts and their reading process from the perspective of the ecological approach to cognition (LÉVY, 2004), thus confronting some views held by authors such as Snyder (1998) and Xavier (2002). Thereby, we try to address aspects related to the reading process, mainly hypertexts, considering impacting factors on both the visual perception system and the cognitive information processing related to written verbal language. Finally, we consider that no reading is linear, since human cognition works by means of associations. Therefore, the reading of both printed and virtual texts can be considered hypertextual.
\end{abstract}

Keywords: Reading. Hypertexts. Visual perception. Cognition. Hypertext comprehension

\section{Referências}

ANDERSON, R. C.; PEARSON, P. D. A Schema-theoretic View of Basic Processes in Reading. In: PEARSON, P. D.; BARR, R.; KAMIL, M. L.; MOSENTHAL, P. (Ed.). Handbook of Reading Research. White Plains, NY: Longman, 1984. p. 255- 291.

BARTLETT, F.C. Remembering: A Study in Experimental and Social Psychology. 
Cambridge University Press. 1933

BUGAY, E. L.; ULBRICHT, V. R. Hipermídia. Florianópolis: Bookstore, 2000.

BURGOS, T. de L. O hipertexto eletrônico de meio ambiente: estratégias de leitura e navegação. 2006. 150f. Dissertação (Mestrado em Letras) - Centro de Ciências Humanas, Letras e Artes, Universidade Federal do Rio Grande do Norte, Natal, 2006. Disponível em: <http://ftp.ufrn.br/pub/biblioteca/ext/bdtd/ TacianaLB.pdf>. Acesso em: 20 jul. 2014.

BUSH, V. As We May Think. 1945. Disponível em: < http://www.ps.uni-saarland. de/ duchier/pub/vbush/vbush.shtml>. Acesso em: 3 set. 2014.

CHARTIER, R. Os desafios da escrita. Tradução de F. M. L. Moretto. São Paulo: UNESP, 2002.

COSCARELLI, C. V. Leitura em ambiente multimídia e a produção de inferências. In: Simpósio Brasileiro de Informática na Educação, 7, 1996, Belo Horizonte. Anais. Belo Horizonte: UFMG, 1996. p. 449-456. Disponível em: <http://www. letras.ufmg.br/carlacoscarelli/publicacoes/SBIE.pdf>. Acesso em: 07 jul. 2012.

COSCARELLI, C. V. (Org.). Hipertextos na teoria e na prática. Belo Horizonte: Autêntica, 2012.

DURAN, G. R. As concepções de leitura e a produção do sentido no texto. Prolíngua. João Pessoa, v. 2, n. 2, p. 1-14, Jul./Dez. 2009.

FACONNIER, G. Mental Spaces: Aspects of Meaning Construction in Natural Language. Cambridge: Cambridge University Press, 1994.

FAIRCLOUGH, N. Media Discourse. London: Edward Arnold, 1989.

FOUCAMBERT, J. A leitura em questão. Porto Alegre: Artes Médicas, 1994.

GOODMAN, K. S. Reading: a psycholinguistic guessing game. In: SINGER, H.; RUDDELL, R. (Ed.). Theoretical Models and Processes of Reading. 2. ed. Newark, Del.: International Reading Association, 1976. p. 497-505.

GOUGH, P.B. One second of reading. In: KAVANAUGH, F.; MATTINGLY, I. G. (Ed.). Language By Ear and By Eye: The relationship between speech and reading. Cambridge, MA: The MIT Press, 1974. p. 33-58.

HUDSON, T. Teaching Second Language Reading. Oxford: Oxford University Press. 2007.

JOHNSON-LAIRD, P. Mental Models. Cambridge, MA: Harvard University Press. 1983. 
KONISHI, M. Strategies for Reading Hypertext by Japanese ESL learners. The Reading Matrix v. 3, p. 97-119, Nov. 2003. Disponível em: <http://www. readingmatrix.com/articles/konishi/article.pdf.>. Acesso em: 18 set. 2014.

KNOBLAUCH, H. Communication, Contexts and Culture. A Communicative Constructivist Approach to Intercultural Communication. in: LUZIO, A. D. GÜNTHNER, S.; ORLETTI, F. (Ed.). Culture in Communication: Analyses of Intercultural Situations. Amsterdam: John Benjamins Company, 2001. p. 3-34.

KOCH, I. G. V. Hipertexto e construção do sentido. Alfa, v. 51, n.1, p. 23-38, 2007.

LEFFA, V. Perspectivas no estudo da leitura: texto, leitor e interação social. In: LEFFA, V.; PEREIRA, A. (Org.). O ensino de leitura e produção: alternativas de renovação. Pelotas: Educat, 1999.

LÉVY, P. O que é o virtual? Tradução de Paulo Neves. São Paulo: 34, 1996.

LÉVY, P. Cibercultura. 34. ed. São Paulo: 34. 1999. Disponível em: <http://pt.scribd. com/doc/11036046/Cibercultura-Pierre-Levy>. Acesso em: 05 set. 2013.

LÉVY, P. As tecnologias da Inteligência - O futuro do pensamento na era da informática. Tradução de C. I. da Costa. São Paulo: 34, 2004. Disponível em: <http:// fisicaemrede.com/file.php/12/Textos/Levy_tecnologias_da_inteligencia.pdf $>$. Acesso em: 07 jul. 2012.

MAKONI, S.; PENNYCOOK, A. (Ed.). Disinventing and Reconstituting Languages. Ontario: Multilingual Matters, 2007.

MARASCHIN, C.; AXT, M. O enigma da tecnologia na formação docente. In: PELLANDA, N.; PELLANDA, E. (Org.). Ciberespaço: um hipertexto com Pierre Lévy. Porto Alegre: Artes e Ofício, 2000. p. 90-105.

MARCUSCHI , L. A. Gêneros textuais emergentes no contexto da tecnologia digital. In: MARCUSCHI , L. A.; XAVIER, A. C. S. (Org.). Hipertexto e gêneros digitais: novas formas de construção de sentido. 2. ed. Rio de Janeiro: Lucerna, 2005. p. 91109.

MINSKY, H. Suggestions for a Cash-Flow Oriented Bank Examinations. In: Proceedings of a Conference on Bank Structure and Competition. Chicago: Federal Reserve Bank of Chicago, 1975

MOITA LOPES, L. P. Oficina de Linguística Aplicada. São Paulo: Mercado de Letras, 1996.

MOWERY, D. C.; ROSENBERG, N. Trajetórias da inovação. A mudança tecnológica nos Estados Unidos da América no século XX. Tradução de M. Knobel. Campinas: Unicamp, 2005. 
NELSON, T. Complex Information Processing: a File Structure for the Complex, the Changing and the Indeterminate. ACM 20th National Conference. 1965 p. 84100. Disponível em: <http://dl.acm.org/citation.cfm?id=806036>. Acesso em: 3 set. 2014.

PAIVA, V.L.M.O. E-mail: Um Novo Gênero Textual. In: MARCUSCHI, L. A.; XAVIER, A. C. (Org.). Hipertexto e Gêneros Digitais. Rio de Janeiro: Lucerna, 2004. p. 68-90.

PINHO, J.B. Publicidade e vendas na internet: técnicas e estratégias. São Paulo: Summus, 2000.

RISAGER, K. Language and Culture: Global Flows and Local Complexities. Clevedon: Multilingual Matters, 2006.

SANTOS, N. A. dos; SIMAS, M L de B. Percepção e Processamento Visual da Forma: Discutindo Modelos Teóricos Atuais. Psicologia: Reflexão e Crítica. 2001 v. 14, n. 1, p. 157-166. 2001. Disponível em: <http://www.scielo.br/pdf/prc/ v14n1/5215.pdf >. Acesso em: 25 jul. 2014.

SMITH, F. Compreendendo a leitura: uma análise psicolinguística da leitura e do aprender a ler. Tradução de D. Batista. Porto alegre: Artes Médicas,1989.

SNYDER, I. (Ed.). Page to Screen - Taking Literacy into the Electronic Era. London and New York: Routledge, 1998.

SOLÉ,I. Estratégias de leitura. Tradução de C. Schilling. 6. ed. Porto Alegre: Artmed. 1998.

STREET, B.V. Cross-cultural Approaches to Literacy. Cambridge: Cambridge University Press, 1993.

TIRABOSCHI, F. F. Instruções de estratégias de leitura hipertextual em língua inglesa: um estudo com aprendizes da educação tecnológica em ambiente virtual de aprendizagem. 2015. 191 f. Dissertação (Mestrado em Letras e Linguística) Faculdade de Letras, Universidade Federal de Goiás, Goiânia, 2015.

XAVIER, A. C. O hipertexto na sociedade da informação: a constituição do modo de enunciação digital. 2002. Tese (Doutorado em Linguística). Campinas: Instituto de Estudos da Linguagem (IEL). Universidade Estadual de Campinas, Campinas, 2002. 
